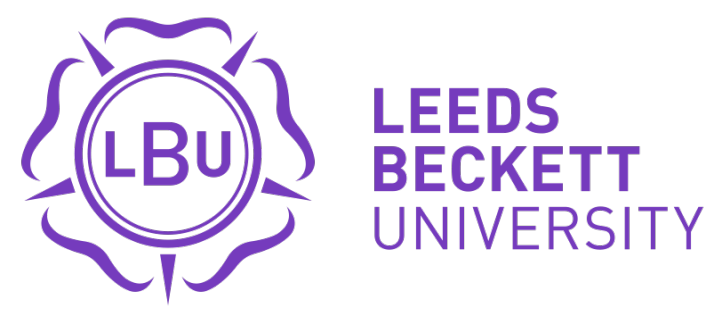

Citation:

Omotayo, TS and Boateng, P and Osobajo, O and Oke, A and Obi, LI (2019) Systems thinking and CMM for continuous improvement in the construction industry. International Journal of Productivity and Performance Management, 69 (2). pp. 271-296. ISSN 1741-0401 DOI: https://doi.org/10.1108/ijppm-11-2018-0417

Link to Leeds Beckett Repository record:

https://eprints.leedsbeckett.ac.uk/id/eprint/7329/

Document Version:

Article (Accepted Version)

Creative Commons: Attribution-Noncommercial 4.0

The aim of the Leeds Beckett Repository is to provide open access to our research, as required by funder policies and permitted by publishers and copyright law.

The Leeds Beckett repository holds a wide range of publications, each of which has been checked for copyright and the relevant embargo period has been applied by the Research Services team.

We operate on a standard take-down policy. If you are the author or publisher of an output and you would like it removed from the repository, please contact us and we will investigate on a case-by-case basis.

Each thesis in the repository has been cleared where necessary by the author for third party copyright. If you would like a thesis to be removed from the repository or believe there is an issue with copyright, please contact us on openaccess@leedsbeckett.ac.uk and we will investigate on a case-by-case basis. 


\title{
Systems thinking and CMM for continuous improvement in the construction industry
}

\begin{abstract}
Purpose: The purpose of this paper is to develop a capability maturity model, with the view of implementing continuous improvement in small and medium scale construction companies (SMSCC) in Nigeria.
\end{abstract}

Design/Methodology/approach: A multi-strategy approach involving qualitative studies of SMSCC in Nigeria was conducted. Semi-structured interviews were conducted with purposively selected construction experts in Nigeria to identify variables essential for continuous improvement in SMSCC. Data collected were thematically analysed using NVIVO. Subsequently, a system thinking approach is employed to design and develop the capability maturity model for implementing continuous improvement SMSCC, by exploring possible relationships between the variables established.

Findings: CMM provided a five-level approach for the inclusion of investigated variables such as team performance; culture; structure; post-project reviews, financial risk management, waste management policy and cost control. These variables are factors leading to continuous improvement in SMSCC, implementable within a six to seven and a half years timeline.

Practical implications: The systems thinking model, revealed cogent archetypes in the form of reinforcing loops which can be applied in developing the performance of SMSCC. Continuous improvement is feasible. However, it takes time to implement. Further longitudinal studies into the cost of implementing continuous improvement through CMM a knowledge transfer project can be initiated.

Originality/value: A methodical strategy for enhancing the effectiveness and operations of SMSCC in developing countries can be extracted from the causal loop diagram and the CMM.

Keywords: Capability maturity model, Continuous Improvement, Kaizen, Nigeria, Systems thinking.

Paper type: Research paper 


\section{Background of the study}

The existence of challenges in construction processes necessitates innovation and change. Considerations of the enormity and impact of cost and time overruns, financing, client satisfaction quality products and project success on construction companies have been the focus of most academics in proffering solutions to mitigate the challenges in the construction industry (Chang and Fan 2017) The suggested panaceas for construction industry issues have been suggested as building information modelling (BIM); post-project reviews; lean construction and automation in construction to mention a few (Chang and Fan 2017; Thunberg et al. 2017). Knowledge sharing in the construction industry (Arif et al. 2017), supply chain management (Reyes and Giachetti 2010), and corporate performance management (Aho 2013) are identified strategies for drving their adoption. However, Capability Maturity Model (CMM) is also an emergent theme in more recent studies when considering continuous improvement through a step-wise approach (Onaopepo et al. 2018). This paper focuses on the latter within construction settings.

CMM was developed by the US Department of defence for software improvement (Sarshar et $a l, 2002)$. Although, CMM was originally designed for the software development industry with great success. CMM application in the construction industry was addressed by (Sarshar et al. 2002) in the standardising process improvement for construction enterprises (SPICE) research. Sarshar et al. (2002) opined that the process of transferring innovation from a sector or country to another involves unboxing the dynamics of applicability and organisational readiness. Consequently, the benefits of innovative approaches such as CMM, may not receive much attention if the cost implications are not positioned to fit the organisational culture and goals (Sarshar et al. 2002; Sun et al. 2009; Arif et al. 2017). Many construction companies across the globe have not been able to adopt BIM, automation and lean construction, considering the cost and time implications of training, experienced staff and technologies to mention a few (Mu'awiya and Yahaya 2013; Bilau and Sholanke 2015). The construction companies in Nigeria are no exceptions. Small and medium scale construction companies (SMSCC) in Nigeria have been massively impacted by the prevailing construction industry challenges. Hence, this study aim to establish a CMM for continuous improvement adoption in Nigerian SMSCC. This investigation is limited to the scope of construction planning and organisational activities associated with continuous improvement. In addition, this investigation will exclude the impact of total quality management on SMSCC in Nigeria to produce a more realistic CMM 
for SMSCC. This is because the aforementioned factor demands an in-depth analysis in a separate investigation.

To achive the stated aim, this paper seeks to address the step-by-step approach in implementing CMM in SMSCC in Nigeria based on a practical application within other construction niches around the world and in Nigeria. An understanding of the various phases of CMM will be beneficial to set variables for the application of CMM in Nigerian SMSCC.

\section{Continuous improvement in the construction industry}

The basic concept of lean construction which is born out of lean production philosophy. The lean production philosophy has various sub-concepts such as just-in-time, responsiveness to change, effective relationship within the value stream, quality management, waste reduction and continuous improvement (Marhani et al., 2012, Marhani et al., 2013). Marhani et al. (2012) supported this by adding last planner system, concurrent engineering, business process reengineering, value-based system, and teamwork as part of the major concepts of lean construction. The five principles of lean construction by Lean Enterprise Institute (2009) as cited by Marhani et al. (2012) include identifying the value, mapping the value stream, create flow, establish pull and seek perfection. These principles have been aimed at focusing on value over cost by reducing non-value added activities thereby creating more client satisfaction; this is the continuous improvement aspect of lean production.

The word "continuous improvement" or kaizen has become common in many organisations in the world. Contrary to the believe of many authors that kaizen started from the Toyota production system (TPS) along with lean production, Shang and Pheng (2013b) argued that kaizen started from the United States when the government started the "training within industry" program during the World War II, before it was brought to Japan. Continuous improvement is not only relevant to performance management but also production management in large corporations and Small and Medium Enterprises (SMEs). Lean thinking and continuous improvement have become a subject which many organisations have harnessed as a tool for improved performances in all divisions. Koskela and Ballard (2012) argued that failure to harness the concept of product in management has led to a lot of challenges in the field of management science for half a century. The use of production techniques such as lean production in construction has been a major subject of discussing in academia. The concept of lean construction has greatly improved the cost, quality, client satisfaction and construction 
project delivery (Sacks, Koskela, Dave, \& Owen, 2010). Studies in the area of lean production in construction involved case studies of various industries other than the construction industry, therefore the benefits highlighted by Sacks et. al (2010) have cut across these industries.

Lean construction has been developed and applied in many construction activities. Al-Aomar (2012) stated that if lean construction has to be appropriately used a framework has to be established, the author further noted that implementation of lean in construction would be further enhanced with Six Sigma rating. The concept of is a broader approach to improving the production system by reducing waste and adding more value. Implementing lean construction has had its debates in the industry and academia. The outcomes of these debates led to the establishment of lean construction in various countries depending on the organisational culture of the construction industries (Sweis, Hiyassat \&Al-Hroub, 2016; Shang \& Pheng, 2014). The difference between lean construction and kaizen in the construction industry depends on is acceptability, organisational culture towards, change, construction company policies and the type of system used. In adopting a lean construction in Chinese construction companies, Shang and Pheng (2014) identified the barriers as "their lack of a long-term philosophy", "the absence of a lean culture in their organisations" and "the use of multi-layer subcontracting". These can be the same for kaizen in the construction industry. However, Shang and Pheng (2014) identified "lack of a supporting culture, compressing schedules, limited resources and especially the lack of professionals with sufficient understanding of kaizen" as the major barriers of kaizen in the construction industry.

Kaizen costing is aimed at reducing cost and creating greater valuable products with the influence of every stakeholder. Although kaizen has not been used in most construction industries, a kaizen model was developed by Vivan, Ortiz, and Paliari (2015) was based on an action research strategy using seventy-six (76) building projects in Brazil. The results showed that the overall cost of the building reduced drastically over the phase of the project. Kaizen costing was applied during construction to reduce cost. Kaizen costing is the cost reduction mechanism of kaizen during production. The model developed by Vivan, et al. (2015) also eliminated the myth of standardisation for production in construction during the action research process. Other authors such as Kaur \& Kaur, (2013); and Savolainen (1999), identified the use of kaizen and kaizen costing for offsite manufacturing of building components and construction. The case studies conducted in a metal industry, a large construction and concrete company by Savolainen (1999), discussed the understanding and adoption of kaizen processes 
empirically. The findings reveal that kaizen adoption process is iterative and the speed of implementation differs in these two companies.

From the review above, kaizen is the overall process of continuous improvement, while kaizen costing is the process of continually improving the cost of production. The process of utilising kaizen and kaizen costing during production is cost-effective but requires detailed housekeeping and identification of problems. The process of using kaizen involve an incremental identification of activities during production for reduction. In construction, overheads present the available gaps where the likely elimination of cost is required.

However, implementing waste reduction through continuous improvement in the construction industry is still in its early stages with numerous challenges.

The case studies conducted in a metal industry, a large construction and concrete company by Savolainen (1999), discussed the understanding and adoption of kaizen processes empirically. The findings reveal that kaizen adoption process is iterative and the speed of implementation differs in the two companies. Kaizen involves continual incremental improvement of the product cost and waste reduction during the execution stage (Kaur and Kaur, 2013). Singh and Singh (2012) collected a number of case studies, surveys and key components of kaizen in the manufacturing and construction sectors in various countries. They noted that kaizen costing focuses on the profit and value a product will give at the manufacturing stage. This process should be part of the management function aimed at improving the product and service delivery. In this case, kaizen costing process will involve the employees and employers' inputs in improving their organisation's performance and handling of financial and non-financial aspects of manufacturing. The use of kaizen costing in these organisations studied by Ellram (2006) is not only limited to the manufacturing process but also the supply chain. Cost reduction in the supply chain is expected to reduce the unit cost of the product. Therefore, kaizen costing is not only within the organisation alone but within other external factors or stakeholders have to be managed along with the performance of the company in reducing cost. Also, the continuous improvement in the number of working hours in an organisation along with the budget of the organisation has created more profits in organisations were used (Budugan, \& Georgescu, 2009). By eliminating non-productive activities productivity improves. Utari (2011) studied the use of kaizen costing in PT. Coca-Cola Bottling IndonesiaCentral, Sumatera. The findings show that eliminated rejected products using kaizen costing 
significantly increased the profit of the company. This process involves identifying what the consumers what and disregarding any component or product which do not add value.

Based on the proven benefits of Kazien manufacturing industries as identified in the aforementioned studies, there is a need for an adequate research in the application of kaizen costing in construction. This method of cost reduction during manufacturing has also been expressed as a strategy for cost control during the same phase.

Examples of continuous improvement in the construction industry protrude from the management phase (known as "gemba kaizen") and the construction phase. Within the construction phase, cost control and activity waste reduction potentially allow the implementation of kaizen. However, the question of implementing continuous in the construction industry clearly presents a research problem. The nature, location, financial status and capacity of a construction company may have influential constraints on implementing continuous improvement. With the strengths of the capability maturity model and a detailed methodology on designing a framework for continuous improvement implementation, the possibilities of alleviating the aforementioned challenges are high.

\section{Bridging the gaps of implementing continuous improvement in the construction industry}

Maturity models are described as a viable approach to improving an organsiation's processes and business process management capabilities (Röglinger, Pöppelbuß \&Becker, 2012). It therefore offers organisations a simple but effective way to possibility measure the quality of their processes (Wendler, 2012). Typically, maturity models consist of a sequence of levels of how an organisation evolve progressively from an initial state to maturity in an anticipated, desired, or logical path (Becker et al., 2009). Hence, patterns of organisational evolution and transformation can be predicted based on the levels in the maturity model.

There are various maturity models documented in literature such as business intelligence and corporate performance management and Capability models; the latter have evolutionary stages which are lacking in the others (Aho 2013). Albliwi et al. (2014) presented a detailed review of literature on maturity models in business process management. De carvalho et al, (2016) on hospital information system, Knowledge transfer (Arif et al., 2017) on Knowledge transfer in construction sector, (Forstner et al., 2014) for process improvement and Oliveira et al. (2014) 
for small and medium enterprises. However maturity models bespoke for implementing continuous improvement in SMSCC settings are rare.

CMM is a level based approach to continuous improvement (Chen \& Fong, 2012; Jia et al. 2011). Although, the model was initially developed to meet the demands of companies operating within the software development industry, Drumond et al. (2018) argued that its methodology can be adapted to other types of organizations. Hence, attempt has been made by the construction industry to adopt this process improvement technique but a major challenges to its adoption is the cost implications (Keraminiyage, Amaratunga, and Haigh, 2005). The five levels of CMM are:

2.1: initial or chaotic, 2.2: planned or tracked, .23: Good practice sharing, 2.4: Quantitatively controlled and 2.5: continuously improving.

The existing maturity modes such as business intelligence and corporate performance management do not have the evolutionary stages as CMM (Aho 2013). Each of these levels reflects the current situation of SMSCC in Nigeria.

\subsection{Initial or chaotic level}

The initial or chaotic level is characterised by a lot of management issues and setbacks (Sun et al. 2009). At this stage, the focus is about the detail of standardisation in terms of a template, organisation, knowledge management, organisational learning, motivation, and strategic planning for future projects (Sarshar et al. 2002). The initial level is also considered as the immature stage, where the SMSCC roughly predicts project costs with very poor cost planning and post-contract cost management activities (Sarshar et al. 2002). The final quality of the buildings constructed are of low quality, clients are unsatisfied and the employees are usually demotivated. This is consistent with Titov et al. (2016) assertion that the initial level represent the poorest performance of the business processes.

\subsection{Planned or tracked Level}

The repeatable stage is the second level. This is also known as planned or tracked (Aho 2013; Sun et al. 2009). Within SMSCC, most challenges faced here is digitisation and learning from the unorganised phase. The drivers for developing the organisation must be determined. New policies are formed for reorganising the construction cost management system in place. At this repeatable phase, the organisation is developed to the point of knowledge management to a considerable extent. This is consistent with Drumond et al. (2018) assertion that organisations 
procedures and processes are held at a minimum specified standard. This suggests that this process will involve some planning and re-organisation. In addition, key performance indicators are also issued to the employees in order to monitor their performance.

\subsection{Good practice sharing Level}

The next level is the defined or good practice sharing. The level 3, has a defined organisation process, which is implemented and monitored. The organisation must develop training programmes at this stage (Sun et al. 2009; Aho 2013). The training programmes in SMSCC may be part of the incurred cost, but it raises the standard of operations within the organisation. The relevant technology in the field of construction cost management should be introduced at this stage.

\subsection{Quantitatively controlled Level}

The management or quantitative level is the fourth level before the final optimisation stage for continuous improvement (Aho 2013; Sarshar et al. 2002). This level makes use of quantitatively controlled activities to enhance the delivery of construction projects within SMSCC. Hence, site office and post-project review meeting are common. Historical cost data from previous construction projects will create an opportunity for organisational learning.

\subsection{Continuously improvement level}

The optimised or continuous improvement level is the fifth level which has the bedrock for continuously improving the organisation (Sun et al. 2009). The feature of this stage is continuous improvement of all process and change management. Change management is the main characteristic of the optimised level (Sarshar et al. 2002; Aho 2013). This is in line with Titov et al. (2016) argument that the continuously improvement level is characterized by the best practices and the highest performance. The changes are rapid and incremental. The incremental process will necessitate quantitative analysis of the previous projects and the identification of waste production activities at regular intervals. All employees of the organisation must be involved in this change management process.

The fifth level can also adopt the plan-do-check act-principle of continuous improvement which technically seeks for gaps within the organisation for redress and monitoring. The CMM approach has the potential to incrementally enhance the profitability of any company if implemented. Scholarly articles on the application of CMM in the Nigerian construction industry have been based on the critical success factors in stakeholder organisation for publicprivate partnership (PPP) and framework development for kaizen implementation by 
(Babatunde et al. 2016; Omotayo, Kulatunga and Bjiermi, 2018). This implies that CMM is very new in the Nigerian construction industry. Therefore, this study will contribute to the understanding and intricacies of CMM within the Nigerian context.

\section{Research methodology}

Qualitative data from survey interviews formed the primary data required to establish variables for CMM based on the outcome of the literature review findings. The structure of this methodology is expressed in Figure 1, as being dependent on the literature review and interviews. Semi-structured interview questions were designed to investigate the existence of continuous improvement in Nigerian SMSCC. Waste reduction policy, organisational culture, and activities concomitant with continuous improvement formed the basis of the interviews. The qualitative data analysis, systems thinking model and CMM lead to the discussion of findings as illustrated in Figure 1.

The Purposive sampling technique for survey interviews provided an advantage for the interviewees to be chosen based on the experience and profession. Eleven (11) Quantity Surveyors and Construction and project managers from SMSCC in Lagos, Nigeria, were interviewed. The respondents have at least fifteen years of experience in the construction industry.

\section{<Insert Figure 1>}

\subsection{Interviews}

The respondents also have qualifications ranging from BSc degree to MSc degree in Quantity Surveying and construction or project management. This is summarised in the table below.

\section{<Insert Table 1>}

The theoretical sampling approach adopted for the semi-structured interview, the years of experience for each of the respondents is essential. Theoretical sampling enables the researcher to get the required knowledge from the experts. This does not depend on the random larger population but very few experts with in-depth views about the subject. The respondents in Table 1 are top executives and principal partners in construction and quantity surveying companies. Some of quantity surveying companies in Nigeria work alongside the contractor. Therefore, the principal partners have been interviewed as part of this study. The interviews 
reached a saturation point when the respondents kept on providing the same feedback. This is attained with the eleventh interviewee.

\section{Analysis and model development}

The interview transcripts were read multiple times by the coders (authors) to capture the participants' views regarding the phenomenon under study and to generate the initial coding scheme from the text data. As a result, content analysis was initially used in this study to identify common patterns that are relevant to the research purpose (Flick 2009) and was facilitated by NVivo 10 to build up a theory from the text data rather than using preconceived themes from the literature. The software package follows the process of importing transcribed sources into a folder, coding the associated sentences into nodes, creating relationships and models. NVivo 10 makes it easy to analyse the presence and understanding of kaizen within SMSCC in Lagos, Nigeria. Using this approach, we coded the identified patterns into different categories and sub-categories (or cases) based on the similarity of codes to make sense of the participants' perceptions and reality. We later defined each category and sub-category to develop themes as agreed by the coders using the research question(s) and purpose as a guide. To achieve the overarching goal of this this study, our analytical procedure as used in this study was consistent with Schmidt's (2004) steps for conducting content analysis as presented below:

a) Categorization of the materials which will be carried out by reading through the transcribed interview and identifying individual aspects which are related to the investigation.

b) The various categories are compiled as themes for the research objective or question.

c) The compiled themes are broken down into nodes or smaller codes which contain detailed information related to the research objective or questions.

d) This coded information was linked together to form cases.

e) These cases are interpreted to give meaning to the research.

Based on the intercoder agreement, Five (5) themes were inferred from the analysis of the qualitative semi-structured interview data. The commonalities in the themes have subcommonalities or sub-themes supporting the findings. For a more comprehensive analysis, brief discussions quoting the interviewees' comments and articles, further justified the themes.

The following themes emerged from the NVIVO 10 analysis process: 
a) Organisational culture

b) Communication approach

c) Waste reduction policy

d) Post-contract cost controlling techniques involving kaizen costing

e) Post-project reviews

\subsection{Organisational culture}

The nature of organisations, in this study, are small and medium scale. This is a major determinant factor in the overall process of implementing kaizen. All eleven (11) respondents categorised the organisational culture in their companies to be a simple one. From the quotes of a director QS6 in a small and medium scale construction, a company in Lagos stated that “... It depends on the communication between the staff and the temporary staff, but our structure is simple." Most small and medium scale organisations have a very small number of staff. They can find it easy to implement new ideas such as kaizen, but they are concerned with the cost of adopting a new process such as kaizen. Respondent QS2 noted that "I think having a new process within my company can be difficult because of the cost, we need to focus the available capital we have on construction projects and paying the salary of workers". Most small and medium scale organisations have a very small number of staff and adopt linear management approach. Hence, should find it easier to adopt new mechanisms of operation, to improve profitability by implement new ideas such as kaizen. According to Kamińska (2015) for kaizen to be productive, constant involvement of all organisation staff is required with adequate support of senior management by providing appropriate and favourable conditions of work and culture. This suggests that organisations with simpler process and even number of staff will find it easier to adopt new mechanisms of operation. However, without top management support, implementing kaizen would be challenging.

\subsection{Communication approach}

The style of communication can be very useful in identifying the presence of kaizen in Nigerian SMSCC. The communication approach can be top-down or bottom-up or non-specific. Eleven (11) interviewees all noted that the top-down approach is the major communication approach within their organisations. According to respondent QS4 who is a chairperson of the company: “...communication within our company is very easy and fluid, but at times it depends on the communication between the staff and the temporary staff, but our structure is simple”. 
In this response, the respondent QS4 also indicated that communication between the staff and other staff who are temporary workers within the office and on the site is very essential. Although, the management of the company can be involved in daily communication via memos as indicated by respondent QS1: “...We send out memos and organise a meeting with the staff. There is no specific pattern of communication..."

The regular meeting in the office and memos are means of communication in Nigerian construction companies (Ugochukwu and Onyekwena, 2014). Respondent QS1 indicated that there is no specific approach within his organisation. In this instance, it cannot be adequate to clearly identify certain problems within the organisation, which can be eliminated. Waste elimination will be very difficult if there is poor communication between workers and the management Four (4) respondents noted that regular memos are sent to the staff on a regular basis. This is based on the number of staff within the organisation. Three interviewees noted that new ideas could easily be communicated freely from the organisation. Kaizen may thrive in this type of organisations based on the acceptance of new innovation and ideas.

\subsection{Waste reduction policy}

In total eight (8) directors interviewed do not have any documented policy on reducing waste in their companies. Not all the eleven (11) respondents gave a direct response to waste reduction within their organisations. Nonetheless, five (5) interviewees noted that time management policy within the company is vital. Time management includes absence, lateness and keeping a working schedule. Only three (3) interviewees have existing waste reduction policy. However, this policy has to do with financial prudence and time management. Respondent PM2 noted that:

“...this is no policy on time management, but we have a documented policy on material waste reduction."

All the three (3) respondents with waste reduction policy review their policies regularly. The concept of waste reduction in an establishment is an element of kaizen. This is related to the employee-employer relationship. In investigating the presence of kaizen within a small and medium scale construction company in Nigeria, identifying waste reduction policies within these organisations gave an inkling of how the management function addresses continuous improvement. Reviewing existing policies on waste reduction gives a clearer understanding of how the system behaves towards cost reduction (Olanrewaju and Anavhe, 2014; Ogwueleka and Maritz, 2016). Effective productivity will lead to the reduction in waste management. 


\subsection{Post-contract cost controlling techniques involving kaizen costing}

In investigating the concept of PC3 within a small and medium scale construction in eleven companies in Lagos Nigeria, provided a broad theme which is "cost monitoring”. Eight (8) out of the eleven respondents noted that cost monitoring of all forms is the major technique for project cost control. During the interview respondent, PM4 stated that:"

...The major technique we use is the conventional way of monitoring project as the project progresses. We also manage variations." The interviewees saw the monitoring process as a process which can be improved over the course of the project through kaizen. The PC3 and monitoring has a lot of external influences on the contracting organisation. Therefore, factors such as interest rates, inflation, fluctuating prices of building materials, exchange rate and government policies on the construction company has massive influences on construction activities (Odediran, Bilau and Sholanke, 2015). Nigerian SMSCC has a lot of challenges. One of which is cost management of projects. Kaizen costing necessitates regular monitoring of construction cost which invariably defines the outcomes of the project. Hence, the vagaries of cost management affect the performance of SMSCC in Nigeria.

\subsection{Post-Project reviews}

The post-project review is a factor for the implementation of continuous improvement. The post-project review is very different from the regular site meetings. It is a general meeting after the entire construction process that is used to evaluate the project performance. Seven (7) interviewees highlighted that post-project reviews are conducted after the end of the project, and it has been having a great impact on their performance in subsequent construction projects. Respondent PM3 stated that: “...Yes, we do organise after project meetings to analyse our performance, and we have been improving on it."

The transcribed interview of respondent PM3 highlighted that the performance of the company has been improving over the years based on post-project reviews. Other respondents such as QS2 also stated that: “...Post-project reviews have a positive impact on our projects, and it gives us the opportunity to identify our mistakes and improve our project delivery."

Post-project reviews are important for continuous improvement within a construction 
organisation (Zhu, Lu and Dai, 2014; Tsao, Rau and Ma, 2015). This aspect creates a channel to implement the tenets of kaizen within a construction establishment.

\section{<Insert Figure 2>}

The themes within the box represented endogenous variables within the system, while the themes outside the dotted lines are exogenous variables influencing the system. For systems thinking, external and internal variables all affect SMSCC. Hence, for continuous improvement implementation through CMM, causal loop diagrams will be used to investigate additional variables and sub-variables.

\section{The systems thinking approach}

The findings from NVIVO 10 provided variables for systems thinking were additional variable was deduced. Systems thinking is applicable for solving complex problems for decision making (Lane, Munro and Husemann, 2016; Joly and Rondó, 2017; Grohs et al., 2018). Organisational culture and policy-making influences decision making. For a comprehensive adoption of continuous improvement, certain factors have to be considered. In systems thinking, there are systems and subsystems (Tetuan et al., 2017; Molderez and Ceulemans, 2018). Hence, the variables which may determine the existence of a system have some sub-variables which are sacrosanct. Systems thinking explores deeper perspectives, internal and external variables and exposes unidentified obstacles to innovation.

The findings in this investigation were based on the conceptual research framework illustrated in figure 1. The CMM development is the research outcome of this study.

The literature review informed that qualitative analysis, the causal loop diagram and CMM. The discussion of findings was also buttressed with the articles from the literature review.

\subsection{Systems thinking: Causal loop diagram for continuous improvement}

Systems thinking is the first initiative to revealing exogenous and endogenous variables existing outside the social phenomenon of qualitative or quantitative investigations (Sheffield et al., 2012; Gerst and Gerst, 2014; Király, Köves and Balázs, 2017). Systems thinking goes beyond the superficial level of visible causalities within an organisation or phenomenon. Sheffield et al. (2012) used the iceberg as an analogy for depicting the four levels of thinking in systems thinking. In Figure 4, the most visible variables within a project or organisation may clearly view events from their perspective. 


\section{<Insert Figure 3>}

The patterns, systematic structure, and mental models are dynamic complexities which require in-depth investigations and cognitive analysis for visibility. Therefore, systems archetypes through causal loop diagrams drive improvement in decision making.

\section{<Insert Figure 4>}

\subsection{Causal loops: Causes effects and reinforcing loops}

The essence of systems thinking is to demonstrate how causal loops represent how causes leads to effects in an organisation (Sheffield et al., 2012; Miki, Kojiri and Seta, 2015; Molderez and Ceulemans, 2018). Construction organisations have varying dynamics which are precursors to challenges. In Figure 5, the causal loop diagram utilised the system boundary variables represented in Figure 3 in developing understanding of the archetypes. According to Sheffield et al., (2012) and Gerst and Gerst, (2014), causal loop diagrams are designed from a generic semantic and the thought process always begins with the positive effect on the preceding variable. Hence, the loops may have a positive or negative reinforcing loop.

\section{<Insert Figure 5>}

Reinforcing loop R1 reflects a continuous causality of efficient financial management with increased financial risk control. When leakages are financial leakages are eliminated, there will be efficient financial management, and this in turn influences the team performance positively. An excellent team performance will create further financial risk control.

\section{<Insert Figure 6>}

Reinforcing loop R2, shows the relationship between the quality of construction cost planning, construction cost control which is supported by monitoring of cost on-site, and efficient financial management leading to improved team performance. If the team is performing well, the quality of construction cost, control and the organisation's finances will improve.

\section{<Insert Figure 7>}

In R3, when efficient organisational culture improves, the quality of the management structure will also improve. This improvement will be felt by the employees and the team performance will further influence the organisational culture. The exogenous variable affecting the loop is 
government regulations. Government policies have a massive influence on organisational culture and can spur immediate change.

\section{<Insert Figure 8>}

Waste reduction during construction can be affected by efficient financial management. Hence, if there is a reduction in waste there will be more opportunities to focus on managing the company's finances as show in R4.

\section{<Insert Figure 9>}

A consistent increment in post-project reviews of cost, schedule and stakeholder's data will enhance the control of cost during construction. This process reinforces a perfect loop for continuous improvement.

\section{$<$ Insert Figure 10>}

In R6, communication can create stakeholder engagement. However, lack of communication can create less stakeholder engagement and less evaluation meetings. This challenges is cyclical and will lead to organisational challenges if it is not addressed.

\section{$<$ Insert Figure 11>}

In reinforcing loop R7, post-project reviews will lead to further waste reductions and hence a continuous improvement process.

\section{$<$ Insert Figure 12>}

\section{<Insert Figure 13>}

\section{$<$ Insert Figure 14>}

Figures, 12, 13 and 14 shows a balancing loop of negative influences form the variables. In B1, if revenue leakages are reduced, there will be more financial control. B2 shows how that if there is an increment in the prices of foreign exchange rate in Nigeria, there will be fluctuations of building material prices and it will be difficult to control cost during construction. Exchange rates have negative influence on the construction industry and hence, PC3. B3 also shows how the exchange rate will lead to lower interest rates in the Nigerian construction industry.

Having reviewed the different archetypes, the CMM will be developed for feasible adoption of continuous improvement in the construction industry. 


\section{The archetypes from the causal loop diagram for the CMM.}

These key variables from R1 to R7 and B1 to B3 were will be transferred to the continuous improvement CMM for SMSCC. Additionally, the trio of the exchange rate, fluctuating prices of building materials and interest rates can only have a reducing effect on continuous improvement when they increase. On the contrary, a reduced interest, exchange and fluctuation of building materials creates additional challenges for the implementation of continuous improvement in SMSCC.

\section{$<$ Insert Figure 15>}

\subsection{CMM for continuous improvement in SMSCC}

Section 2 explicated the levels of attaining optimisation of a system. An SMSCC is an example of a system and CMM extend beyond the limited variables invested using qualitative studies and NVIVO. Systems thinking provided an extensive analysis into outlining and intricate variables transferrable to circumstances in developing construction economies. Hence, the exclusion of Nigeria in the semantics of SMSCC after the NVIVO analysis.

The cross-functional flowchart enabled visual representation of the CMM for the realisation of continuous improvement in SMSCC. The levels discussed in section 2 will be used to discuss each section of the model as displayed in figure 11.

\section{Discussion of findings}

\subsection{Level 1- Initial and Chaotic}

Based on the causal loop diagrams and the CMM interactions, the cybernetics of organisational culture improvement is synonymous to understanding the need for change and creating a strategy for adapting to change. At the initial level, SMSCC will definitely review project delivery and organisational financial standing. This review is not an evaluation or post-project review. The systems theory underpins CMM and systems thinking. Gregory (2000) posits that systems theory is a cybernetic interaction between mechanical, organic and social systems with the environment. Gregory (2000) further explained that "there are three main systems 
perspectives that are usually applied in the business context - mechanistic (sometimes known as closed), organismic and adaptive (the last two being examples of open systems). All three provide public relations with valuable insights". In relation to the initial level in CMM, a clear identification of project and organisational challenges is the transition from mechanistic to organismic and adaptive systems. However, within the mechanistic system, interactions with the outside environment influenced decision making leading to other levels within the CMM.

Organisational management and financing of the project is one of the leading causes of liquidation and bankruptcy in SMSCC around the world (Marri, Gunasekaran and Kobu, 2003; Rostami et al., 2015). In Nigeria and other developing economies, SMSCC has staffing issues, communication and project delivery challenges (Ojo, 2013; Bilau and Sholanke, 2015). Job satisfaction in SMSCC is very low. External forces of government regulations, interest rates, fluctuation of building materials and exchange rate constantly produce a project of a lower standard and dissatisfied clients.

Even though the management of SMSCC at level 1 phase may identify these challenges, appropriate steps in mitigating identified challenges will them lead the SMSCC into an organismic and adaptive system. The organismic and adaptive systems will be open to innovation and change. Problem realisation will clearly delineate the consequences of inactions and continuous existence in a mechanistic system. Some SMSCC may not move to level two of keep track of all project and organisational activities. Maintaining the status quo truly defined the mechanistic organisational system. Yearly, an SMSCC existing in the chaotic phase of CMM will continually experience the same challenges and inactions until their demise. Although change requires strategic management for implementation, alternative solutions towards resolving the identified challenges necessitate openness towards standardisation.

\subsection{Level 2-Repeated}

Level 2 is the planned or repeated phase of CMM. At this level of openness to change is established. The 5s of kaizen which is sort; set in order; shine; standardise, and sustain are set in motion at this phase of CMM.

Sorting involves some basic housekeeping within the office or a construction site. Sorting involves identification of lapses and creation of avenues for keeping identified lapses in order (Suárez-Barraza, Ramis-Pujol and Kerbache, 2011). This leads to set things in order for monitoring (shine) and evaluations (Topuz and Arasan, 2013). Standardisation pertains to planning templates for repeated activities and establishing basic policies for managing minor 
setbacks in the organisation are formulated as part of the standardisation phase. Standardisation is very essential in executing projects. Organisational growth and evaluation are based on standardised processes established during project execution (Filho and Waterson, 2018). Hence, the fifth "S" of kaizen being sustained is repeated within organisational growth and evaluation (Higuchi, Nam and Sonobe, 2015; Jiménez et al., 2015). Standardisation leads to systemisation through data and knowledge management. Standardisation creates room for the increase in further standardisation. However, the systemisation of SMSCC will necessitate a well-defined strategic management policy. Therefore, level 3 in CMM may be attained. Although continuous improvement is not achieved at this stage, basic policies for setting continuous improvement in motion are established at this phase.

\subsection{Level 3- Defined}

More open bottom-up communication approach will be outputs of strategic management policies built on standardisations. The third level is the stage where the SMSCC are implementing policies for the construction cost management. The policies which are well defined are consistent with industry standards and regulations. The PC3 template is integrated with the use of technology. The technology can be measurement software such as Cost X, CATO, VECTOR and CAD measure. These will reduce the measurement inaccuracies to a minimum. The PC3 template can make use of PRIMAVERA, spreadsheets or any other project management software to monitor the actual work done on site and juxtapose it with the working budget. Training cost may be incurred as a result of this defining phase. However, improvements in cost and design management coupled with client satisfaction will be attained.

Strategic definition of how waste will be mitigated on construction sites and in the office has to implemented and reviewed yearly. Furthermore, level 3 represents the beginning of continuous improvement after a comprehensive organisational evaluation. The challenges of organisational improvement can be readdressed by formulating policies leading to the creation of organisational learning. Organisational learning entails creating a knowledge base of tacit and explicit data for continuous improvement purposes. These data can be captured from a previous project, yearly review, staff performance and review, and the organisation's performance (Lai, Aziz and Chan, 2014). Detailed management of knowledge within an organisation provides avenues for improvement. 


\subsection{Level 4- Managed}

The fourth level is the "managed level". This is where continuous improvement begins on a quantitative level, intermittent reviews and evaluations are based on quarterly performance and are regular (Filho and Waterson, 2018). Metrics are used for quantitative performance review and KPIs are development for future projects and members of staff. Performance review of the planning and construction team will involve working along with new technologies, knowledge of improving the existing structure of construction cost management.

At this stage, financial risk management becomes very sacrosanct for organismal performance and attainment of optimisations. Many organisation is this level may begin to use big data for predicting future outcomes and organisational growth. Hence, the managed level potentially sets in motion waste management activities on the construction site. These waste management activities primarily work on eliminating non-value adding activities during construction.

The concept of kaizen is further strengthened to promote the attainment of continuous improvement. Further emphasis should be placed on cost planning, control, and PC3. This trio affects the management and delivery of construction projects (Gurcanli, Bilir and Sevim, 2015; Hosny, Ibrahim and Fraig, 2016). Additionally, decision-making systems for construction project management and the SMSCC will be improved at this stage. The decision support systems which may be based on previous and existing data within the organisation potentially creates opportunities to seek continuous improvement in the fifth stage.

\subsection{Level 5- Optimised}

The final level is the "optimised level". This level has created the foundation for formal continuous improvement within the office and on site. Data is stored and reused just as the defined level which involves creating new policies for PC3. This level is all about implementation of plan-do-check-act principle broken down to continuous improvements in the office and construction sites.

The kaizen in the office (gemba kaizen) starts with identifying the problems that need improvement within the office. The management or any other employee can identify this problem. The identified problem should be stored in a file or computer system for record purposes, and delegated for resolution. This delegation can be sent as a memo or email within the office. A kaizen supervisor can tackle the problem by looking at the non-value added activities within the office. The decision-making process here will be to schedule activities for 
immediate review or have a brainstorming session with the employees in the next function. At this stage, more problems can be identified in the office for resolution. The problems can be some activities that take more time and has led to financial losses. Therefore, time management, resource allocation, financial management, and other wasteful processes have to experience effective management. The management will be involved in this brainstorming meeting with the supervisors and other employees. The findings of the session have to be implemented and monitored for further actions. The implementation and monitoring aspect is carried out the supervisors and the employees. The process can end here or continue with more data stored for future use. This process of identifying the process in the office and having immediate resolution with implementation should happen regularly for effective.

Post-project reviews are the bedrock of continuous improvement (Tsao, Rau and Ma, 2015; Füllemann et al., 2016). When an organisation decided to review the content of construction project data, through intensive quantitative and qualitative evaluations; address pressing concerns from all stakeholders; redress all setbacks experienced during construction projects; and implements the outcomes in future projects, then continuous improvement has begun. The act of post-project review is intensive and extensive communication. Post-project reviews afford SMSCC cheaper ways of implementing continuous improvement. Communication is very crucial in adapting to change. Therefore, at the optimised level of CMM, the creation of change is definite through effective communication. Post-project reviews also give a clearer pathway to re-organising SMSCC for optimal productivity.

The pan-do-check act principle in continuous improvement re-wires the organisation through effective teamwork, management and immediate resolutions of problems, and promotes waste reduction for financial management and the mitigation of exogenous variables such as interest rate, exchange rate and fluctuating prices of building materials. Financial risk management is applicable in mitigating the trio of interest rates, exchange rate and fluctuating prices (Chan et al., 2011; Treacy, Spillane and Tansey, 2016). The impact of policies and continuous improvement are further reviewed for the future implications of the construction project.

The optimised level also makes use of data from the planned or tracked level (level 2). A cyclical process of using post-project reviews to fully implement change in an SMSCC is reached in the fifth level.

\section{Guidelines for continuous improvement implementation using CMM}


The function flow chart model presenting CMM in Figure 11 requires an additional guideline to clearly show the implementation roadmap. The guideline is based on probable assumptions on long it may take for an SMSCC to remain in a CMM stage.

The guidelines in Table 2 reveal that it may take up to 6 to 12 months for an SMSCC to fully realise prevailing challenges in the initial stage. The repeated phase can also take up to 12 months for an SMSCC to move from the phase.

Phase three may take up to 24 months because of the volume of policymaking, evaluations, changes and template creation. The fourth phase may also take up to 18 months to attain from the defined phase. Contentious issues may arise at the managed phase during performance reviews. Furthermore, implementation will take a lot of time. The optimised phase potentially adopts continuous improvement and will definitely take several months for the SMSCC to phase into optimisation.

\section{<Insert Table 2>}

Having the guideline in table 2 also reveals that it may take six (6 years) to seven and a half years (7.5 years) for full implementation of continuous improvement in an SMSCC.

\section{Conclusion}

The most important finding in this study is the plausible application of continuous improvement in SMSCC in developing countries. Although this finding may be limited to developing countries, the plan-do-check-act principle explicated in the discussion section are transferrable to any construction organisation irrespective of its location. There are cost implications of adopting continuous improvement, however, this is beyond the scope of this study. Notwithstanding, the findings of continuous improvement in construction in SMSCC within the context of the literature review, qualitative analysis and model synthesis all agree that post-project review is a major driver for continually improving a construction organisation. Further studies into strategic adoption of post-project reviews in the construction industry should realign the policies of construction organisation towards continuous improvement. The enormous data in construction companies can be used to develop an artificial intelligence to aid post-project reviews. The value of this study is inherent in the cybernetic interactions between all the major variables for continuous improvement within and outside and organisation. A construction organisation interacts with 
itself as an entity and other external forces before it can improve. This clarity which is expressed expressed in the causal loop diagrams is the exclusivity of this research.

\section{References}

Ajayi, S. O., Oyedele, L. O., Bilal, M., Akinade, O. O., Alaka, H. A., Owolabi, H. A., \& Kadiri, K. O. (2015), Waste effectiveness of the construction industry: Understanding the impediments and requisites for improvements. Resources, Conservation and Recycling, Vol. 102, pp. 101-112.

Albliwi, S.A., Antony, J. and Arshed, N. (2014), "Critical literature review on maturity models for business process excellence", Industrial Engineering and Engineering Management (IEEM) Proceedings of the IEEE International Conference, Hong Kong, December, pp. 79-83.

Andawei, M. (2014), "Project cost monitoring and control : A case of cost / time variance and earned value analysis", IOSR Journal of Engineering (IOSRJEN), Vol. 4 No. 2, pp. 22-25.

Arif, M., Al Zubi, A., Gupta D., Egbu C., Walton R.O., Islam R., (2017) "Knowledge sharing maturity model for Jordanian construction sector", Engineering, Construction and Architectural Management, Vol. 24 Issue: 1, pp.170-188, https://doi.org/10.1108/ ECAM-092015-0144

Babalola, O., Ibem, E. O., \& Ezema, I. C. (2018), Implementation of lean practices in the construction industry: A systematic review. Building and Environment.

Babatunde, S. O., Perera, S. and Zhou, L. (2016), Methodology for developing capability maturity levels for PPP stakeholder organisations using critical success factors, Construction Innovation, Vol. 16. No. 1, pp. 81-110

Bilau, A. and Sholanke, A. (2015), "Review of Shortage of Skilled Craftsmen in Small and Medium Construction Firms in Nigeria", Journal of Environment and Earth Science, Vol. 5 No. 15 , pp. $98-111$.

Chen, L., \& Fong, P. S. (2012). Revealing performance heterogeneity through knowledge management maturity evaluation: A capability-based approach. Expert Systems with Applications, Vol. 39 No. 18, pp. 13523-13539.

Dakhli, Z., Lafhaj, Z. and Bernard, M. (2017), "Application of lean to the bidding phase in building construction: a French contractor's experience", International Journal of Lean Six Sigma, Vol. 8 No. 2, pp. 153-180.

De Carvalho, J.V., Rocha, Á. and de Vasconcelos, J.B. (2016), "Maturity models for hospital information systems management: are they mature?”, in Chen, Y.-W., Tanaka, S., Howlett, 
R.J. and Jain, L.C. (Eds), Innovation in Medicine and Healthcare, 2015, Springer International Publishing, New York, NY, pp. 541-552

Ding, Z., Yi, G., Tam, V. W., \& Huang, T. (2016). A system dynamics-based environmental performance simulation of construction waste reduction management in China. Waste management, Vol. 51, pp. 130-141.

Drumond, G. M., Méxas, M. P., Meiriño, M. J., \& Quelhas, O. L. G. (2018), Maturity of the book purchasing process in university libraries. Knowledge and Process Management, Vol. 25 No. 1, pp. 54-63.

Filho, A.G. and Waterson, P. (2018), "Maturity models and safety culture: A critical review", Safety Science, Vol. 1 No. 105, pp. 192-211.

Forbes, L.H. , Ahmed, S.M. and Barcala, M. (2002), “Adapting lean construction theory for practical application in developing countries", in Division of Building Technology, CSIR (Eds), Proceedings of the First CIB W107 International Conference: Creating a Sustainable Construction Industry in Developing Countries, Stellenbosch, pp. 11-13

Forstner, E., Kamprath, N. and Röglinger, M. (2014), "Capability development with process maturity models - decision framework and economic analysis", Journal of Decision Systems, Vol. 23 No. 2, pp. 127-150

Füllemann, D. Fridrich, A., Jenny, G. J., Brauchli, R., Inauen, A. and Bauer, G. F. (2016), "The relevance of intervention participants' process appraisal for change in well-being and lean work processes of entire teams", Journal of Organizational Effectiveness: People and Performance, Vol. 3 No. 4, p. null.

Gerst, R. M. and Gerst, R. M. (2014), "Deming' s systems thinking and quality of healthcare services : a case study", Leadership in Health Services, Vol. 26 No. 3, pp. 204-219.

Gregory, A. (2000), "Systems theories and public relations practice", Journal of Communication Management, Vol. 4 No. 3, pp. 266-277.

Grohs, J. R. Kirk, G. R., Soledad, M. M. and Knight, D. B. (2018), "Assessing systems thinking: A tool to measure complex reasoning through ill-structured problems", Thinking Skills and Creativity, Vol. 1 No. 28, pp. 110-130.

Gurcanli, G. E., Bilir, S. and Sevim, M. (2015), "Activity based risk assessment and safety cost estimation for residential building construction projects", Safety Science, Vol 1. No. 80, pp. 1-12.

Heigermoser, D., de Soto, B. G., Abbott, E. L. S., \& Chua, D. H. (2019), BIM-based Last Planner System tool for improving construction project management. Automation in Construction, Vol. 104, pp. 246-254.

Higuchi, Y., Nam, V. H. and Sonobe, T. (2015), "Sustained impacts of Kaizen training", Journal of Economic Behavior \& Organization, Vol 1, No. 120, pp. 189-206. 
Hosny, H. E., Ibrahim, A. H. and Fraig, R. F. (2016), "Cost analysis of continuous flight auger piles construction in Egypt", Alexandria Engineering Journal, Vol. 55 No. 3, pp. 27092720.

Jia, G., Chen, Y., Xue, X., Chen, J., Cao, J., \& Tang, K. (2011), Program management organization maturity integrated model for mega construction programs in China. International Journal of Project Management, Vol. 29 No. 7, pp. 834-845.

Jiménez, M. Romero, L., Domínguez, M., Del Mar Espinosa, M. (2015), "5S methodology implementation in the laboratories of an industrial engineering university school", Safety Science, Vol 1. No. 78, pp. 163-172.

Joly, M. and Rondó, P. H. (2017), "The future of computational biomedicine: Complex systems thinking", Mathematics and Computers in Simulation, Vol. 1 No. 132, pp. 1-27.

Kaizen World. (2016), What is 5S? Retrived from https://www.kaizenworld.com/what-is5s.html [Accessed on 9 , Novembver 2018

Kamińska, B. (2015), Kaizen as a method of management improvement in small production companies. Przedsiebiorczosc i Zarzadzanie, Vol. 16 No. 2, pp. 157-170.

Kavuma, A., Ock, J., \& Jang, H. (2019), Factors influencing Time and Cost Overruns on Freeform Construction Projects. KSCE Journal of Civil Engineering, Vol. 23 No. 4, pp. 1442-1450.

Kehinde, O. J., Adegbuyi, A. A., Fadeyi, O. I., and Adegbuyi, O. A. (2016), "Nigerian SocioEconomic Development : The Roles and Challenges of Small and Medium Entreprises Development Agency of Nigeria( SMEDAN )", in 3rd International Conference on African Development Issues, Convenant University, Sango-Otta, Nigeria, pp. 217-221.

Király, G., Köves, A. and Balázs, B. (2017), "Contradictions between political leadership and systems thinking", Journal of Cleaner Production, Vol 2017 No. 140, pp. 134-143.

Koskela, L. (1992), Application of the new production philosophy to construction. Stanford: Stanford university. Vol. 72.

Lai, H. Y., Aziz, A. R. and Chan, T. K. (2014), "Effect of the global financial crisis on the financial performance of public listed construction companies in Malaysia", Journal of Financial Management of Property and Construction, Vol 19 No. 3, pp. 246-263.

Lane, D. C., Munro, E. and Husemann, E. (2016), "Blending systems thinking approaches for organisational analysis: Reviewing child protection in England", European Journal of Operational Research, Vol. 251 No. 2, pp. 613-623. 
Lu, W., \& Tam, V. W. (2013), Construction waste management policies and their effectiveness in Hong Kong: A longitudinal review. Renewable and sustainable energy reviews, Vol. 23, pp. 214-223.

Marri, H. B., Gunasekaran, A. and Kobu, B. (2003), "Implementation of computer-integrated manufacturing in small and medium enterprises", Industrial and Commercial Training, Vol. 35 No. 4, pp. 151-157.

Marzouk, M., \& Azab, S. (2014). Environmental and economic impact assessment of construction and demolition waste disposal using system dynamics. Resources, conservation and recycling, Vol. 82, pp. 41-49.

Mehralian, G. Nazari, J. A., Nooriparto, G. and Rasekh, H. R. (2017), "TQM and organizational performance using the balanced scorecard approach", International Journal of Productivity and Performance Management, Vol. 66 No. 1, pp. 111-125.

Miki, Y., Kojiri, T. and Seta, K. (2015), "If Thinking Support System for Training Historical Thinking", Procedia Computer Science, Vol. 60 No. 1, pp. 1542-1551.

Molderez, I. and Ceulemans, K. (2018), "The power of art to foster systems thinking, one of the key competencies of education for sustainable development", Journal of Cleaner Production, Vol. 186 No. 1, pp. 758-770.

Nikakhtar, A., Hosseini, A. A., Wong, K. Y., \& Zavichi, A. (2015), Application of lean construction principles to reduce construction process waste using computer simulation: a case study. International Journal of Services and Operations Management, Vol. 20 No. 4, pp. 461-480.

Nudurupati, S., Arshad, T. and Turner, T. (2007), "Performance measurement in the construction industry: An action case investigating manufacturing methodologies", Computers in Industry, Vol. 58 No. 7, pp. 667-676.

Ogwueleka, A. C. and Maritz, M. J. (2016), "Modeling for incentive payoffs in the Nigerian construction industry", Journal of Engineering, Design and Technology, Vol. 14 No. 3, pp. $543-562$.

Ojo, J. (2013), "Organisational Culture , Job Satisfaction and Commitment of Lagos-based Construction Workers", IOSR Journal of Business and Management, Vol. 13 No. 6, pp. 108120.

Olanrewaju, A. A. and Anavhe, P. J. (2014), "Perceived claim sources in the Nigerian construction industry", Built Environment Project and Asset Management, Vol. 4 No. 3, pp. 281-295. 
Omotayo, T., Kulatunga, U. and Bjeirmi, B. (2018), Critical success factors for Kaizen implementation in the Nigerian construction industry, International Journal of Productivity and Performance Management, Vol. 67 No. 9, pp. 1-20.

Perkins, I., \& Skitmore, M. (2015). Three-dimensional printing in the construction industry: A review. International Journal of Construction Management, Vol.15 No. 1, pp. 1-9.

Rostami, A., Sommerville, J., Wong, I. L. and Lee, C. (2015), "Risk management implementation in small and medium enterprises in the UK construction industry", Engineering, Construction and Architectural Management, Vol. 22 No. 1, pp. 91-107.

Sarhan, J., Xia, B., Fawzia, S., Karim, A. and Olanipekun, A. (2018), "Barriers to implementing lean construction practices in the Kingdom of Saudi Arabia (KSA) construction industry", Construction Innovation, Vol. 18 No. 2, pp.246-272.

Savolainen, T. I. (1999), Cycles of continuous improvement. International Journal of Operations \& Production Management, Vol. 19 No. 11, pp. 1203-1222.

Shang, G., \& Sui Pheng, L. (2014), Barriers to lean implementation in the construction industry in China. Journal of Technology Management in China, Vol. 9 No. 2, pp. 155-173.

Sheffield, J., Sankaran, S. and Haslett, T. (2012), "Systems thinking : taming complexity in project management", On the Horizon, Vol. 20 No. 2, pp. 126-136.

Shen, L. Y., Tam, V. W., Tam, C. M., \& Drew, D. (2004), Mapping approach for examining waste management on construction sites. Journal of construction engineering and management, Vol. 130 No. 4, pp. 472-481.

Shen, L. Y., Tam, V. W., Tam, C. M., \& Drew, D. (2004), Mapping approach for examining waste management on construction sites. Journal of construction engineering and management, Vol 130 No. 4, pp. 472-481.

Shingo, S. (1984), Study of Toyota Production System, Japan Management Association, Japan.

Suárez-Barraza, M. F., Ramis-Pujol, J. and Kerbache, L. (2011), "Thoughts on kaizen and its evolution: Three different perspectives and guiding principles", International Journal of Lean Six Sigma, Vol. 2 No. 4, pp. 288-308.

Tauriainen, M., Marttinen, P., Dave, B., \& Koskela, L. (2016), The effects of BIM and lean construction on design management practices. Procedia engineering, Vol. 164, pp. 567-574.

Titov, S., Bubnov, G., Guseva, M., Lyalin, A., \& Brikoshina, I. (2016), Capability maturity models in engineering companies: case study analysis. In ITM Web of ConferencesVol. 6, p. 3002 .

Topuz, C. and Arasan, Z. (2013), "Kaizen-educational: An Awareness-raising and Motivational-enhancement Group Counseling Model", Procedia - Social and Behavioral 
Sciences, Vol. 84 No. 1, pp. 1356-1360.

Treacy, D., Spillane, J. P. and Tansey, P. (2016), "Construction disputes in small to medium enterprise's in Ireland during recession: Identification of critical factors", International Journal of Law in the Built Environment, Vol. 8 No. 1, pp. 21-41.

Tsao, L., Rau, P. L. P. and Ma, L. (2015), "Development of a Quick Instrument Measuring Kaizen Culture (for Chinese)", Procedia Manufacturing, Vol. 3 No. 1, pp. 4708-4715.

Ugochukwu, C. S. and Onyekwena, T. (2014), "Participation of Indigenous Contractors in Nigerian Public Sector Construction Projects and Their Challenges in Managing Working", International Journal of Civil Engineering, Construction and Estate Management, Vol. 1 No. 1, pp. 1-21.

Wang, J., Li, Z., \& Tam, V. W. (2014). Critical factors in effective construction waste minimization at the design stage: a Shenzhen case study, China. Resources, Conservation and Recycling, Vol. 82, pp. 1-7.

Waris, M., Khamidi, M. F. and Idrus, A. (2016), "The Cost Monitoring of Construction Projects through Earned Value Analysis", Journal of Construction Engineering and Project Management, Vol. 2012 No. 2, pp. 42-45.

Yahaya, H. D., Geidam, M. M. and Usman, M. U. (2015), "The Role of Micro, Small and Medium Enterprises in the Economic Development of Nigeria", International Journal of Small Business and Entrepreneurship Research, Vol. 4 No. 3, pp. 33-47.

Yuan, H. (2013), Critical management measures contributing to construction waste management: Evidence from construction projects in China. Project Management Journal, Vol. 44 No. 4, pp. 101-112.

Zhu, Y., Lu, Z. and Dai, H. (2014), "Improving Efficiency and Patient Satisfaction in a Peripherally Inserted Central Catheter Center Using Lean-Based Methodology", Journal of the Association for Vascular Access, Vol. 19 No. 4, pp. 244-255. 


\section{List of Figures}

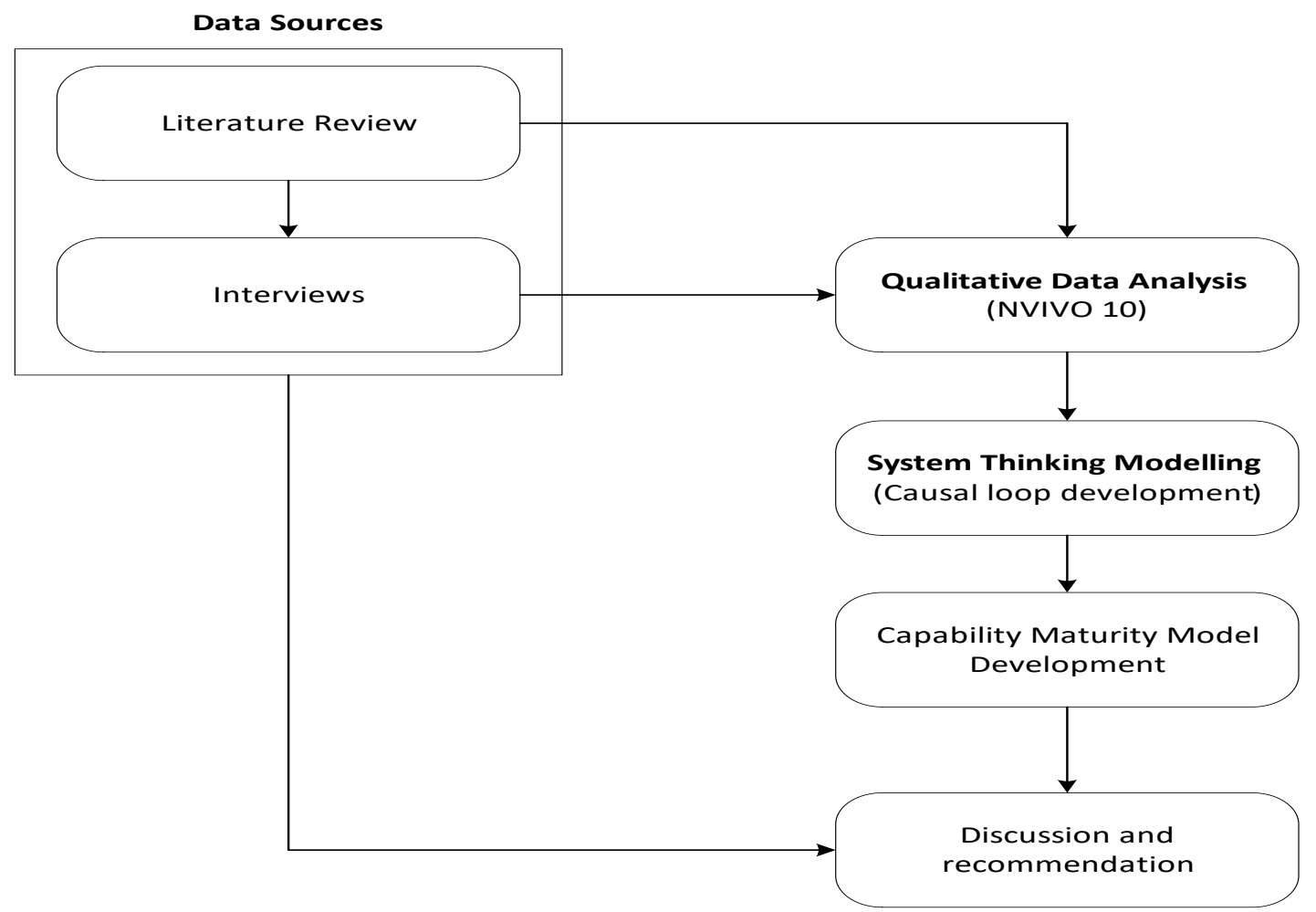

Figure 1. The conceptual framework based on NVIVO 10 analysis, systems thinking and capability maturity model

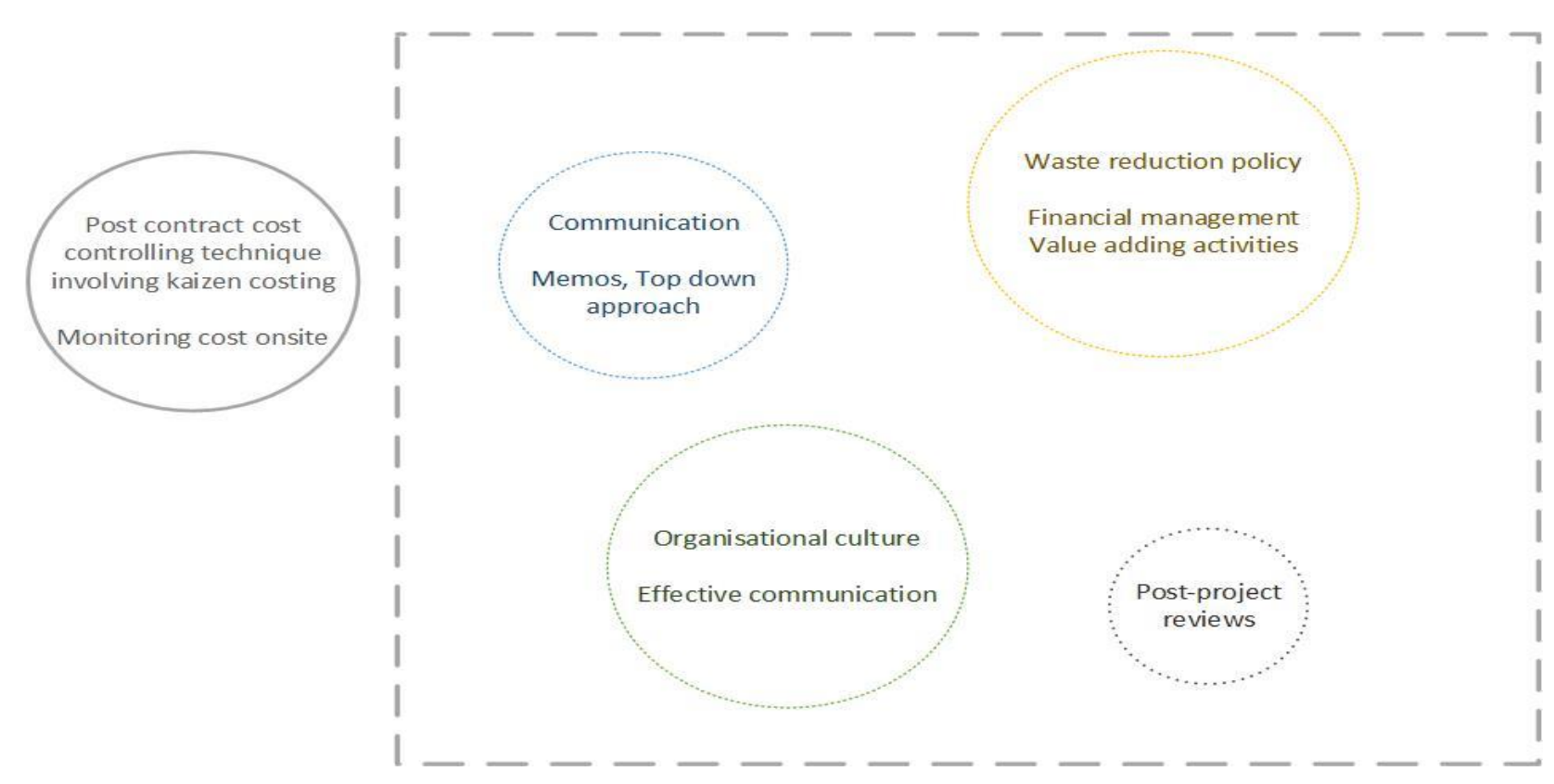

Figure 2. Themes represented as internal and external influences. 


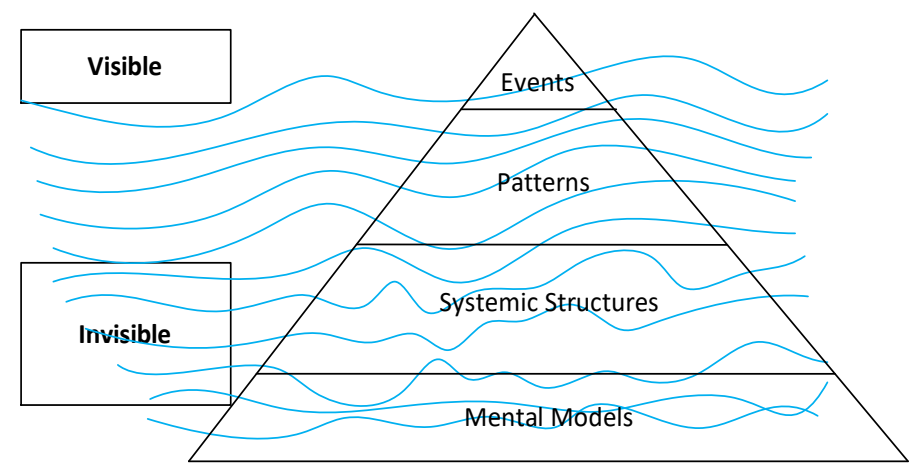

Figure 3. The iceberg model by Sheffield et al. (2012) 


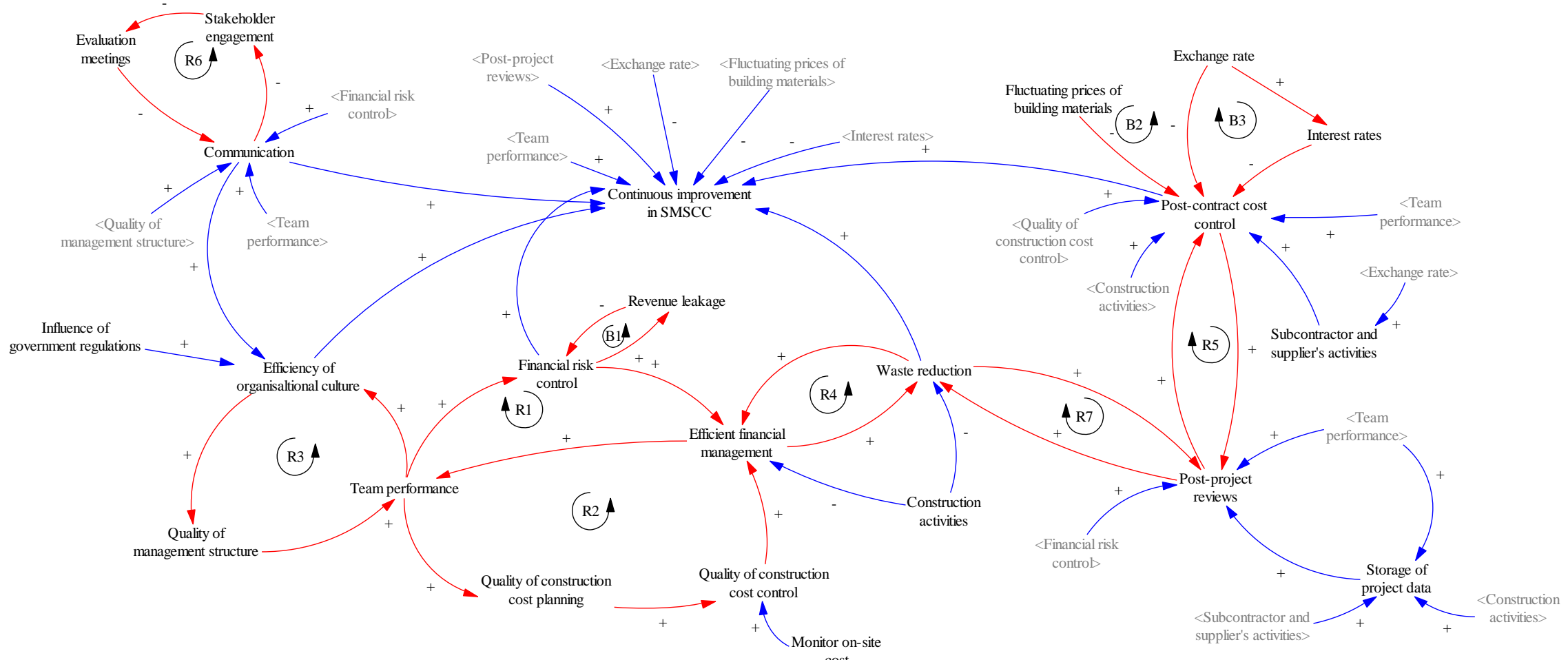

Legend:

A causal relationship

$+(-)$ signs at the arrow heads indicate that the effect is positively (negatively) related to the cause.

$\mathbf{R}$ denotes a reinforcing loop

Figure 4. A system thinking causal loop diagram for continuous improvement variables 


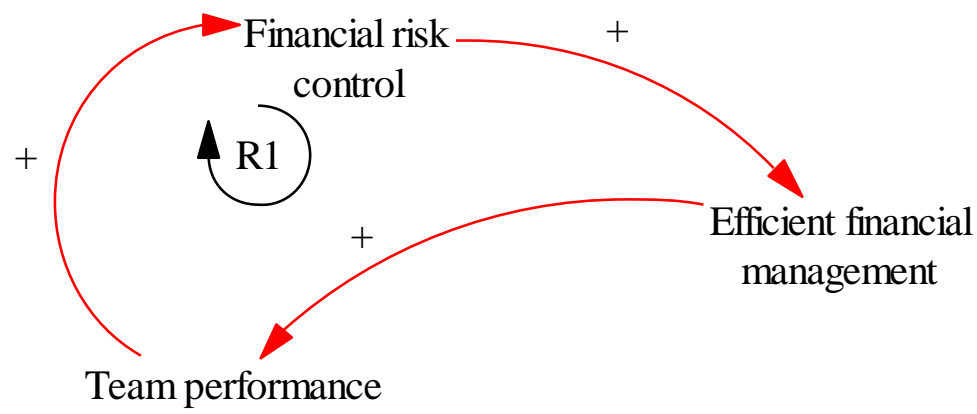

Figure 5. Reinforcing loop RI

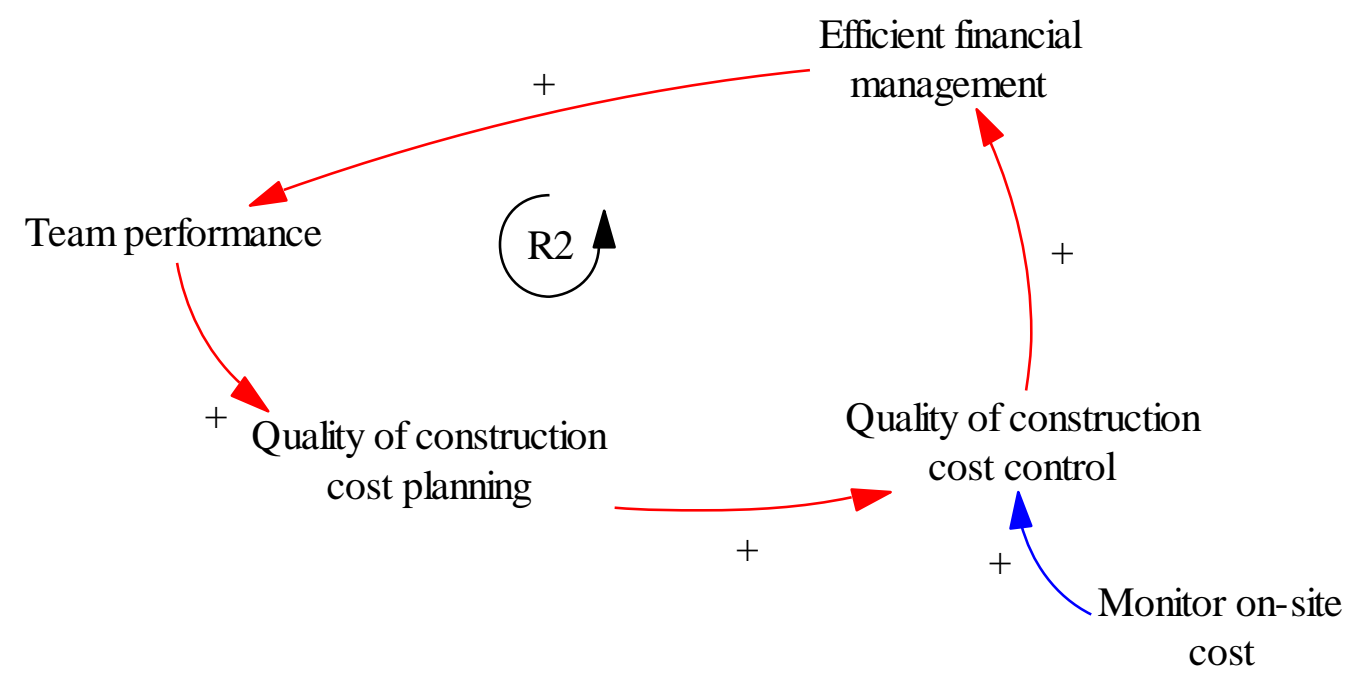

Figure 6. Reinforcing loop R2 
Influence of government regulations

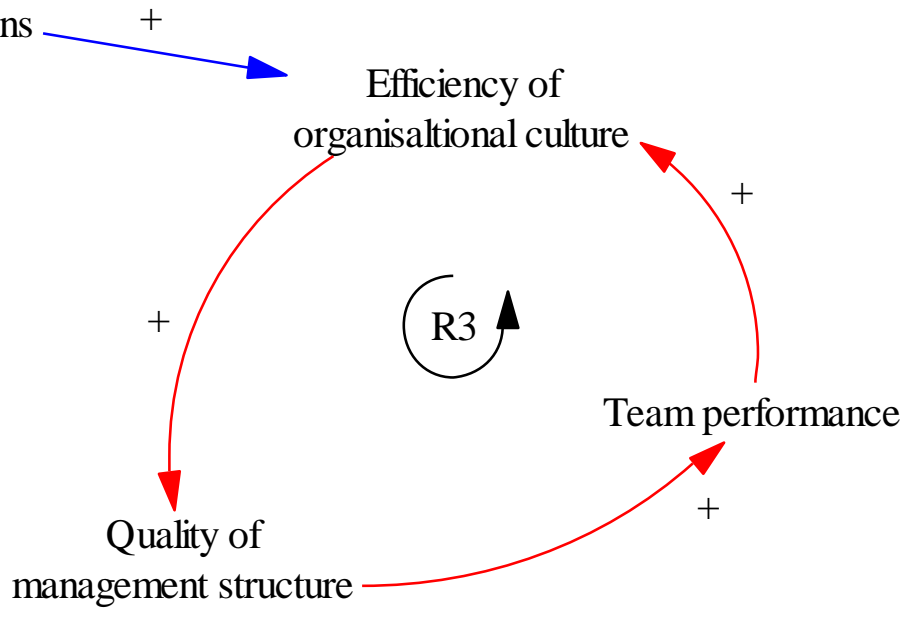

Figure 7. Reinforcing loop R3

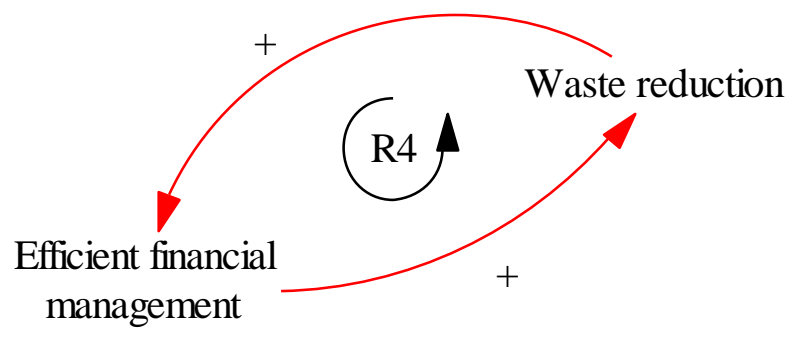

Figure 8. Reinforcing loop R4 


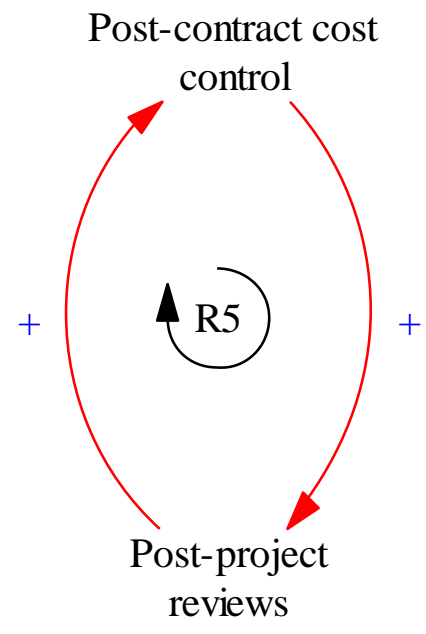

Figure 9. Reinforcing loop R5

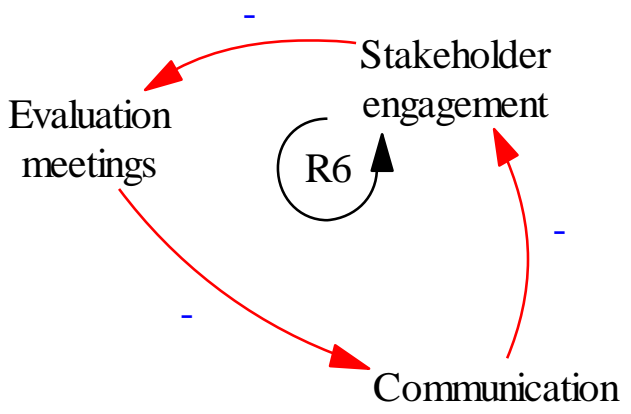

Figure 10.. Reinforcing loop R6

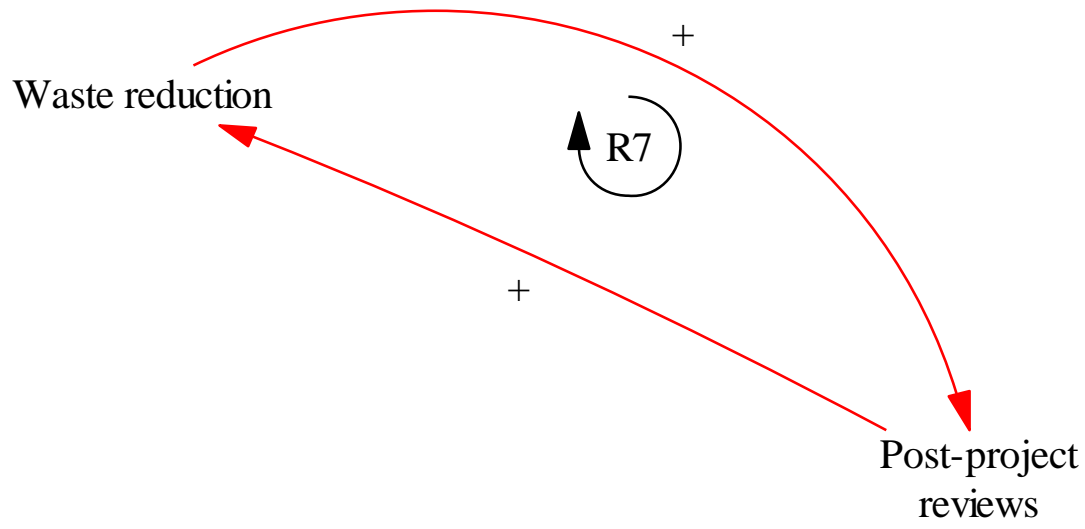

Figure 11. Reinforcing loop R7 


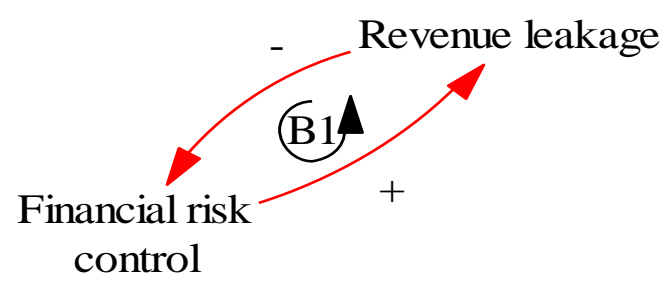

\section{Figure 12. Balancing loop B1}

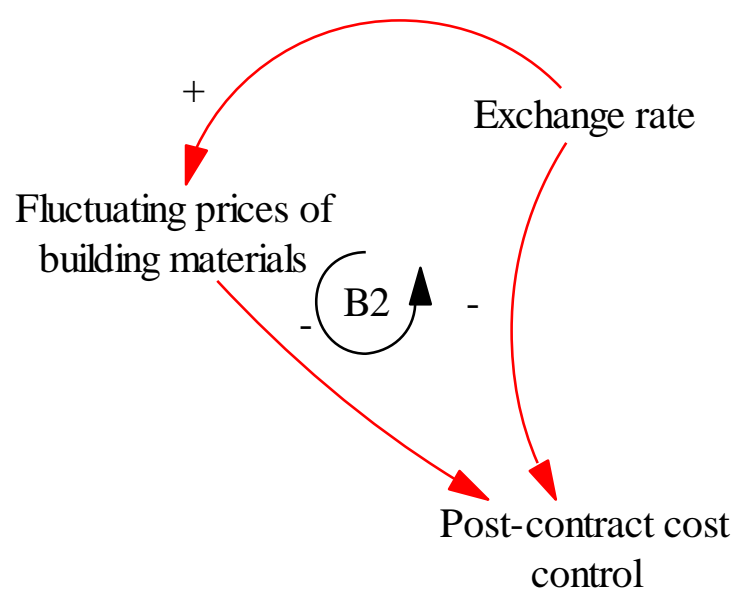

Figure 13.. Balancing loop B2

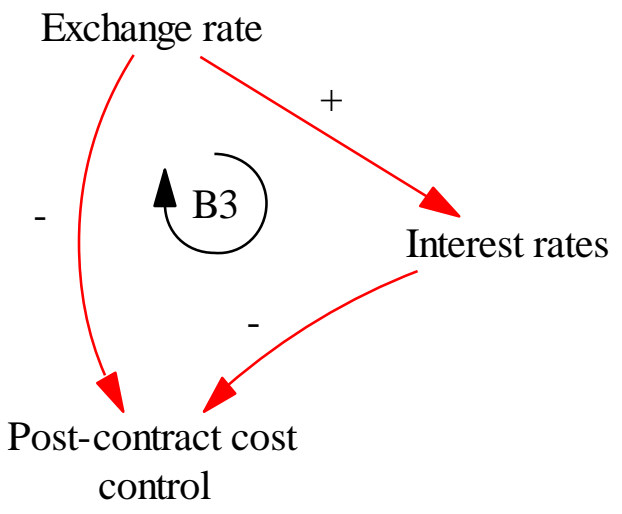

Figure 14. Balancing loop B3 



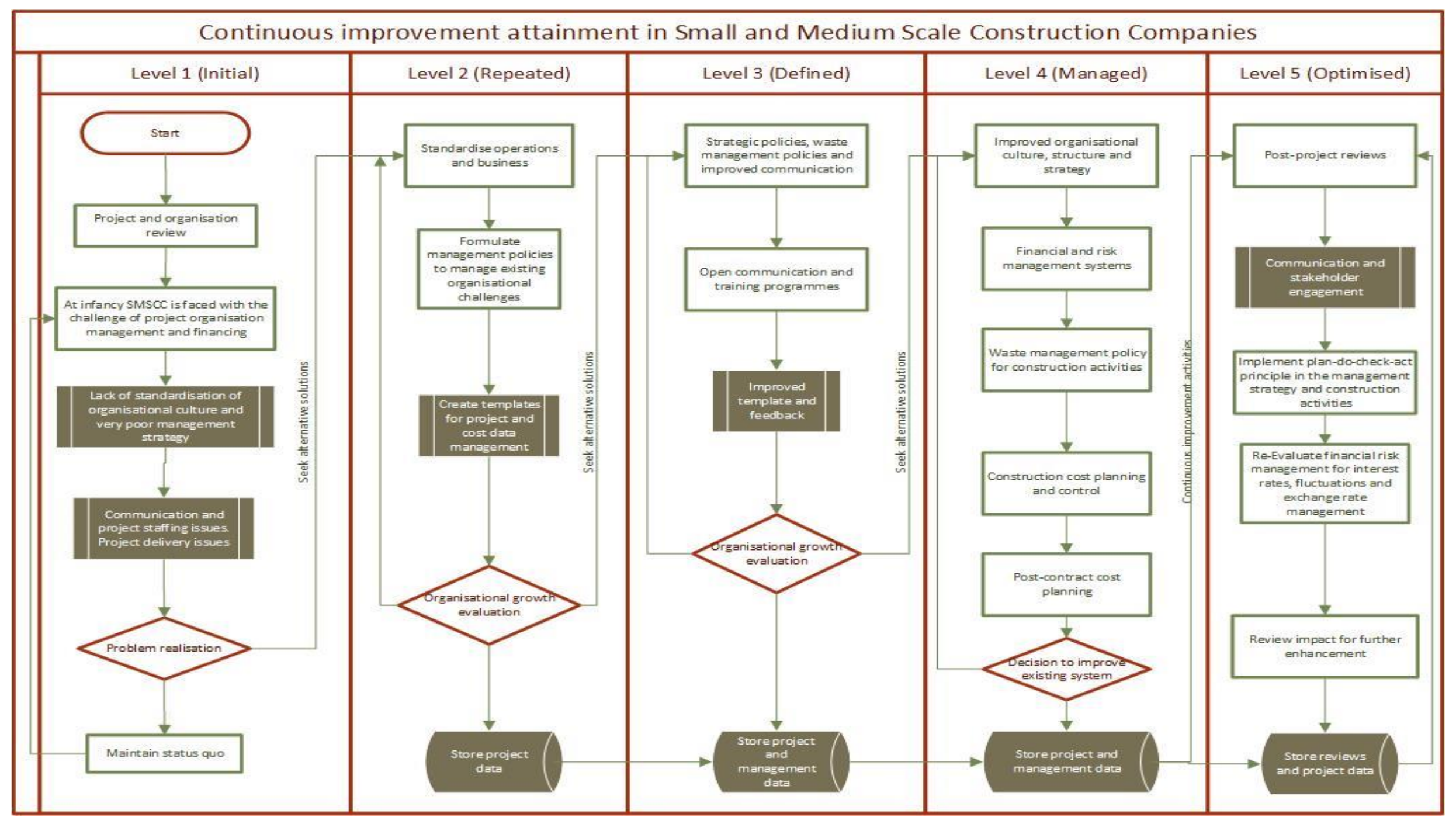

Figure 15. Capability maturity model levels for SMSCC continuous improvement 


\section{List of Tables}

Table 1.Interviewees' profile.

\begin{tabular}{|c|c|c|c|c|c|c|c|c|c|c|c|c|c|c|c|}
\hline \multirow[t]{2}{*}{ Profession } & \multirow[t]{2}{*}{ Code } & \multicolumn{7}{|c|}{ Job Role } & \multirow[t]{2}{*}{ Y.e } & \multicolumn{2}{|c|}{$\begin{array}{c}\text { Highest } \\
\text { Qualification }\end{array}$} & \multicolumn{4}{|c|}{ Project Type } \\
\hline & & MD & GM & PP & $\mathrm{C} / \mathrm{D}$ & $\mathrm{C}$ & $\mathrm{AD}$ & $\mathrm{D}$ & & $\mathrm{MSc}$ & $\mathrm{BSc}$ & $\mathrm{BC}$ & $\mathrm{BCE}$ & A & RH \\
\hline \multirow{6}{*}{$\begin{array}{l}\text { Quantity } \\
\text { Surveyor } \\
\text { (QS) }\end{array}$} & QS1 & $\sqrt{ }$ & & & & & & & 15 & $\sqrt{ }$ & & & $\sqrt{ }$ & & \\
\hline & $Q S 2$ & & & $\sqrt{ }$ & & & & & 17 & & $\sqrt{ }$ & $\sqrt{ }$ & & & \\
\hline & $Q S 3$ & & & $\sqrt{ }$ & & & & & 23 & & $\sqrt{ }$ & $\sqrt{ }$ & & & \\
\hline & $Q S 4$ & & & & & $\sqrt{ }$ & & & 29 & & $\sqrt{ }$ & $\sqrt{ }$ & & & \\
\hline & QS5 & & & & & & $\sqrt{ }$ & & 17 & $\sqrt{ }$ & & & $\sqrt{ }$ & & \\
\hline & QS6 & & & & & & & $\sqrt{ }$ & 23 & & $\sqrt{ }$ & & $\sqrt{ }$ & & \\
\hline \multirow{5}{*}{$\begin{array}{l}\text { Project } \\
\text { Manager } \\
(\mathrm{PM})\end{array}$} & $P M 1$ & $\sqrt{ }$ & & & & & & & 20 & $\sqrt{ }$ & & $\sqrt{ }$ & & & \\
\hline & PM2 & & $\sqrt{ }$ & & & & & & 21 & $\sqrt{ }$ & & $\sqrt{ }$ & & & \\
\hline & PM3 & $\sqrt{ }$ & & & & & & & 15 & & $\sqrt{ }$ & & & $\sqrt{ }$ & \\
\hline & PM4 & & & & $\sqrt{ }$ & & & & 25 & $\sqrt{ }$ & & & & & $\sqrt{ }$ \\
\hline & PM5 & & $\sqrt{ }$ & & & & & & 19 & & $\sqrt{ }$ & & & & $\sqrt{ }$ \\
\hline
\end{tabular}

Legend: $M D=$ Managing Director; $G M=$ General Manager; $P P=$ Principal Partner $C=$ Chairman; $C / D=$

Contractor/Director; $A D=$ Assistant Director; $D=$ Director $;$ Y.e $=$ Years of experience $; B C=$ Building construction; $B C E$

= Building and civil engineering; $A=$ airport, $R H=$ Residential housing. 


\begin{tabular}{|c|c|c|c|}
\hline Levels & Name & Action points & Timeline \\
\hline 1 & Initial & $\begin{array}{l}\text { At this stage, the small and medium scale construction company is experiencing several managerial, financial and } \\
\text { project delivery challenges. The logical thing to do is to seek alternative ways of doing business }\end{array}$ & $\begin{array}{l}6-12 \\
\text { Months }\end{array}$ \\
\hline 2 & Repeatable & $\begin{array}{l}\text { Standardisation leading to systemisation of operations and management. The challenges were identified in level } 1 \text {, } \\
\text { and measure is put in place to address the challenges. This measure will lead to the formulation of policies which } \\
\text { will require the creation of standard and templates for the construction company. Data management should begin } \\
\text { at this level. }\end{array}$ & 6-12 months \\
\hline 3 & Defined & $\begin{array}{l}\text { This stage is where kaizen critical success factors are implemented after training activities. The benefit if kaizen } \\
\text { training within the organisation will definitely outweigh the cost over time. The critical success factors are } \\
\text { improving the management of the company through the motivation of workers in terms of salary and working } \\
\text { conditions. This is followed by the enhanced of the operations by reducing waste in every respect. Monitor the } \\
\text { business ethics; this should also be improved with cost information for ethical reasons, such as overpricing and } \\
\text { fraud. Lastly, the construction cost management should be enhanced with the removal of avoidable claims and } \\
\text { management of project cost on site. Data management should improve here. }\end{array}$ & 24 months \\
\hline 4 & Managed & $\begin{array}{l}\text { The standardised policies on waste will lead to improved performance metrics for employees and projects. The } \\
\text { management of the data gathered within four years plus should create an organisational learning environment. }\end{array}$ & $\begin{array}{l}12-18 \\
\text { months }\end{array}$ \\
\hline 5 & Optimised & $\begin{array}{l}\text { Post-project reviews should be conducted and implemented at this level. This is where kaizen costing activities on } \\
\text { the construction site are implemented with the plan-do-check-act process (plan-do-check-act process). This would } \\
\text { be thought in the kaizen costing training. The kaizen costing process should be embedded in the traditional post- } \\
\text { contract cost control process. }\end{array}$ & $\begin{array}{l}24 \text { months } \\
\text { and above }\end{array}$ \\
\hline
\end{tabular}

\section{Table 2. Guidelines for kaizen implementation in SMSCC}

